\title{
Environmental protection in the integrated mechanization of technological processes of high-rise construction
}

\author{
Ruben R. Kazaryan ${ }^{1, *}$ and Vitaly Khvan $^{1}$ \\ ${ }^{1}$ Moscow State University of Civil Engineering, 26 Yaroslavskoe shosse, Moscow, 129337, Russia
}

\begin{abstract}
Construction is a complex and multifaceted activity, in which a great many diverse specialists are involved, each of which is a professional in its scientific and practical field. One of such areas is the actual and rather popular in our time high-rise construction, which serves various selfsufficient sub-areas of activity. In the paper, the problems of parity and priority that arise during the construction process are considered on the example of the interaction of two of them (integrated mechanization of technological processes of erecting high-rise buildings and protecting the environment). Parity involves balancing the situations, circumstances, costs, forces, and capabilities of each of these components of activities in the overall process of constructing a high-rise building. A global confrontation between these concrete sub-areas of construction activity is not permissible. But dialectically, the priority of one of them over the other, according to the goal-setting, naturally arises at each particular moment or period of construction production. The order of their implementation in time is formed, presupposing concentrating precisely on those goals that are more important and significant at the moment. This aspect of activity is called a priority.
\end{abstract}

\section{Introduction}

The unity and struggle between the concepts of "parity" and "priority" accompanies a person throughout his life. He constantly struggles with the desire to correspond to the whole variety of self-sufficient applications of his mental and productive labor activity (their parity) and the impossibility of simultaneous realization of this diversity (that is, forced choice of priorities in the process of making rational decisions). This aspect is inherent in all types of activities, in particular - construction (including high-rise construction).

Parity (lat. Paritas - equality) states the equality of the relationship of two or more manifestations on some parameters without any confrontation.

Priority (lat. Prior - the first, senior) shows the expediency of focusing on those goals that are most important and significant at the moment. There are models for selecting priorities, one of which is shown in Figure 1.

\footnotetext{
*Corresponding author: r.kazarian@mail.ru
} 


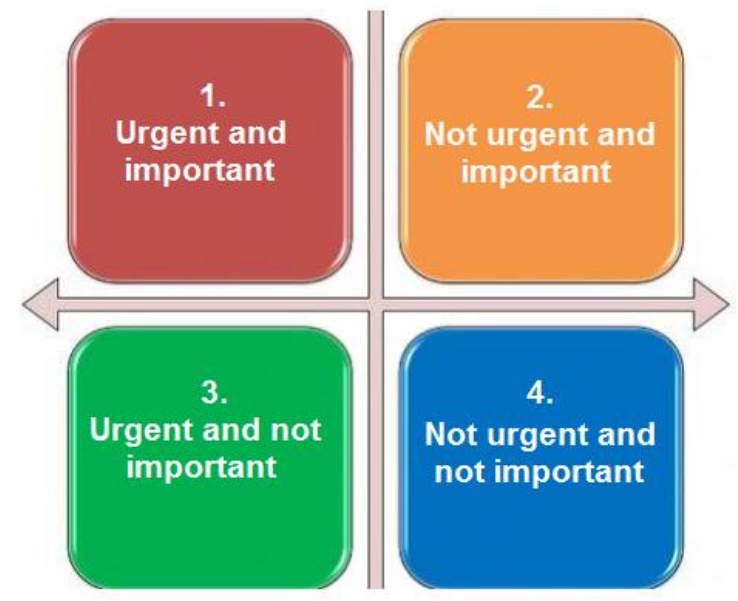

Fig. 1. The model for identifying priorities

Observance of the grounded interaction of these two important concepts in construction activities is one of the important components of the art of managing construction production $[1-3,7-12]$.

\section{Materials and methods}

High-rise construction is impossible without the use of various means of mechanization and transportation, lifting mechanisms and machines designed to ensure the productive work of the builder. The introduction into the construction industry of a complex of technical means and technological measures that replace manual labor with mechanized or automated forms the essence of complex mechanization in the construction industry.

The main and auxiliary processes and operations of construction production, within the framework of complex mechanization, carry out sets of machines and mechanisms that are interrelated in terms of productivity and operational parameters. In the organizational and technological documentation for construction and installation works of high-rise construction, their complex mechanization is a part of the standard package for the construction technological complex.

Normokomplektom consider the totality of means of mechanization, devices, instruments and hand tools, designed to perform a certain type of construction and installation work in accordance with the adopted technology and the possible highest performance [1-9, 11, 12].

In due time TsNIIOMTP has developed and released collections of standard sets for different types of construction and installation works, the most relevant model projects and specialized teams. In the same place the "Unified nomenclature of means of mechanization" was developed, which is divided into interspecific means and special equipment by types of construction and installation works.

The mechanisms and structures developed by the leading design organizations and recommended for application for any kind of construction and assembly work (forging workplaces for height, lifting devices, means of containerization and packaging, in-vehicle transport, means of individual and collective protection, containers for storing and supplying materials, etc.). Special equipment is oriented to different types of construction work (earth, concrete, erection, plastering, painting, stone, carpentry, roofing and waterproofing, tile, glass, sanitary, road, flooring, wallpaper and other work). 
These standards are not mandatory, are recommendatory in nature, they are supplemented with the development of technology and new technologies for high-rise construction.

The choice of conditions for the application of normocomplexes and the necessary calculations (productivity for specified volumes of work, coordination of technical parameters of machines, determination of their quantity, etc.) are carried out in production projects and technological maps for private and specialized flows for each technological complex of work.

In the set of machines can interact in series or in parallel (Figure 2).
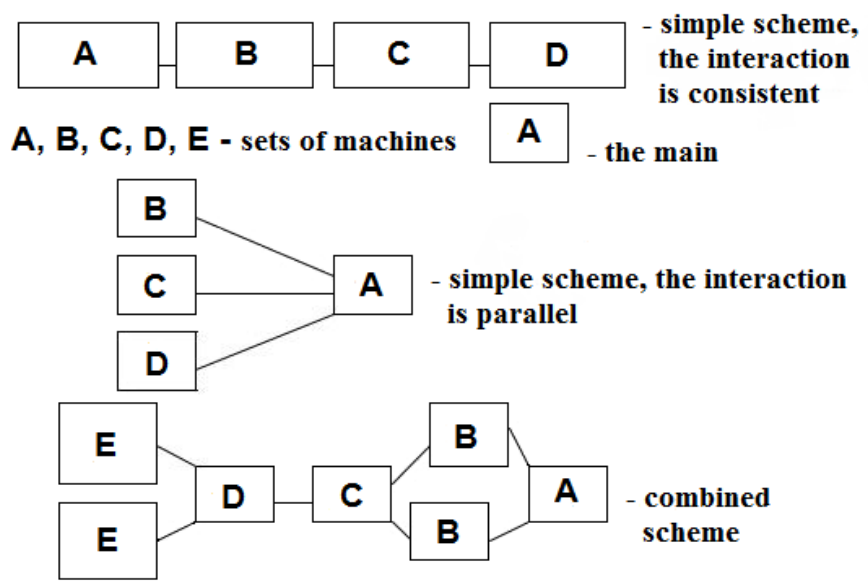

Fig. 2. The structure of complex mechanization

When interacting in a sequential scheme, a simple one machine calls the simple whole set. Machines in a parallel circuit operate independently of each other, except for the main (master).

The choice of the composition of normocomplexes implies: determination of the scheme of complex mechanization and basic parameters of the set of machines (main, auxiliary and additional); comparative technical and economic assessment and selection of the optimal option; linking small mechanization facilities in terms of productivity and technical parameters with the main set of machines.

When selecting normocomplexes, an important point is to assess the impact of means and technologies of integrated mechanization on the environment (nearby buildings and structures, labor resource of construction production and the population of adjacent territories, air and water basins, soils with established hydrological regime, flora, fauna, etc.) $[1-3,7-15]$.

\section{Discussion}

The pathogenic influence on the above components of the environment in the conditions of parity can be exerted by: increased noise background, the dynamic impact of operating mechanisms, emissions of large volumes of dust particles of different fractions and gases into the atmosphere, the generation of numerous building debris and debris), various toxic) wastewater in the sewerage network and on the soil, disturbance of the existing geological and hydrological conditions $[1-3,7-12,14,16,17]$.

In order to reduce the noise level, machines and mechanisms with low noise characteristics are used, an electric drive is used, night work is prohibited, vibro-pile driving or screw-fastening piles are used. 
Install standing containers for construction waste and debris and, as they are being filled, they transport containers to urban landfills, landfills or construction waste collection points. Contractor organizations conclude contracts with local administrations for the use of landfills and landfills, indicating the planned amount of waste.

In cases of unauthorized release (dumping), mixed with the ground water floods adjacent areas and clogs storm sewers. It happens that the volume of waste can exceed the capacity of existing drainage and sewerage networks, and in the new construction of such networks, there may not exist at all. Therefore, it is necessary to organize a drain from the construction site at the preparatory stage and to reconstruct the drainage in advance.

At the construction site, it is necessary to install washing areas for motor vehicles, construction machinery and handling equipment, and to resolve the issue of removal of domestic water from the towns of builders and premises of the administrative and economic apparatus. During the work, any discharge of water, solutions and mixtures that do not conform to the established drainage schemes should be prohibited.

At the same time, it is not always possible to adapt the technologies of construction production to the requirements of the habitat. For example, it may be necessary to use explosive destruction technology in the preparatory period of construction and in the execution of works of the zero cycle. Therefore, it is recommended to do such work in the morning, when the population of the surrounding territories in the overwhelming majority is no longer sleeping or departing to the place of work.

When carrying out the vertical lay-out of the construction site, they disturb the natural state of the soil and the terrain. Therefore, in the project of erecting a high-rise building, it is necessary to envisage reclamation of the territory after construction.

State standards for the protection of the environment under "land reclamation" mean a set of works aimed at restoring their productivity and national economic value. Work in the allotted areas is related to the disturbance of the soil cover, therefore, in the process of preparatory work, special attention should be paid to the collection and conservation of not only vegetative soil, but also potentially fertile layers.

The developer is obliged not to allow pollution and clogging of the removed fertile soil layer with construction waste, to exclude the possibility of its mixing with the non-absorbent soil during cutting, transportation or after laying in the hurts.

The technical stage of reclamation involves the planning of dumps, the filling of upland and drainage channels, the removal of large-sized debris of rocks and production structures, their subsequent disposal or storage, covering the surface with uniform fertile soil layers, sowing grasses, restoring shrub and tree vegetation, and planting new crops. Then follows the biological stage of land reclamation (liming and gypsum, application of organic and mineral fertilizers) [1-3, 5, 7-12, 17-19].

It is strictly forbidden to dig in the ground in the planning and burning of waste and residues of building materials on the construction site.

\section{Conclusions}

The person (the designer, the organizer, the foreman, etc.) prioritizes, determining what needs to be done immediately, which can wait a little, and what can be done in the last place. Without complex mechanization of technological processes, the construction of high-rise buildings can not be imagined. Violation of the ecology of the environment (including nature and the labor resource of the construction organization) is unacceptable. The problem of parity and priority of complex mechanization of technological processes of erection of objects and protection of the environment, in itself, is important in construction activities. But in high-rise construction, due to its increased organizational and technological complexity, this problem acquires special significance [20-25]. 


\section{References}

1. V.I. Telichenko, O.M. Terentev, A.A. Lapidus Technology of erection of buildings and structures 446 (2004)

2. G. Maas, F. van Gassel ISARC Value creation by automation and robotics in construction 310-315 (2004)

3. A.A. Volkov, V.O. Chulkov, R.R. Kazaryan, M.A. Fachratov, E.K. Rahmonov App. Mech. \& Mat. 584-586 pp 2387-2390 (2014)

4. A.A. Potovalov, S.V. Tabakov Technology and mechanization of the erection of buildings and structures (2016)

5. W.M.M. Frijns, A.A. van Nordennen, B. van Schijndel, E. Schuurmans Research Report on High Rise Construction (2005)

6. R.R. Kazaryan, I.A. Bun'kina Sci. Rev. 7 (2016)

7. L. van Hilten, T. Schevenhoven Combining functions in high-rise projects (2005)

8. P.Y. Choi, E. Frank, B. Dijkgraaf, R. van Bakel ISARC Masterproject Hoogbouw. Vergelijking van de continenten (2005)

9. J.A.H. van Boxtel, T.P.J. Cloosterman, J.S. Dol, L.B.F. Driessen How to play with the big guys (2005)

10. F.F.H. Griemink, L.M.C. Hamelton, J.J. Mestebeld, W.L.G.H. Slotman, W.J. van de Siepkamp CM \& E. Res. Group High-rise construction analysed: critical success factors (2005)

11. R. Haesenbos, J. Hagen, S. Jost, T. Rams, M. Schaffner CM \& E. Res. Group Ecological high-rise construction (2005)

12. E. S. Kosonogova The Interpretation of financial statements as an object of studies $\mathrm{p}$ $466(2013)$

13. Order of the Ministry of Finance of the Russian Federation On Approval of the program for federal accounting standards development for public sector organizations 64 (2015)

14. Order of the Ministry of Finance of the Russian Federation On Approval of Rules for preparation and refinement of the program for Federal accounting standards development for public sector organizations 45, (2015)

15. B.A. Lyovin, R.R. Kazaryan, V.O. Chulkov Infographics of anthropotechnical management. Infographic modeling in the mental activity philosophy. 1 (2016)

16. B.A. Lyovin, R.R. Kazaryan, V.O. Chulkov Conception of advanced development of anthropotechnical security of functioning and life quality. 2 (2016)

17. B.A. Lyovin, R.R. Kazaryan, V.O. Chulkov Anthropotechnical management as a means of provision of activities service. $\mathbf{3}$ (2016)

18. G. Maas ISARC Technical developments in high-rise building (2005)

19. MRDS 02-08 Manual for scientific and technical support and monitoring of buildings and structures under construction, including large-span, high-altitude and unique

20. Urban Development Code of the Russian Federation No. 190-FZ of 29.12. (2004)

21. TCH 45-1.03-109-2008 (02250).

22. Federal Law No. 384-FZ "Technical Regulations on the Safety of Buildings and Structures" of 30.12.2009

23. Federal Law No. 384-FZ "Technical Regulations on the Safety of Buildings and Structures" of 30.12. (2009) 